\title{
Risk of cardiovascular malformations after exposure to paroxetine in pregnancy: meta-analysis
}

\author{
Nitesh Painuly, ${ }^{1}$ Ritu Painuly, ${ }^{2}$ Reinhard Heun, ${ }^{1}$ Pratap Sharan ${ }^{3}$
}

The Psychiatrist (2013), 37, 198-203, doi: 10.1192/pb.bp.111.035915

${ }^{1}$ Derbyshire Healthcare NHS Foundation Trust, Derby, UK; ${ }^{2}$ Royal Derby Hospital, Derby, UK; ${ }^{3}$ All India Institute of Medical Sciences, New Delhi, India

Correspondence to Nitesh Painuly (nitesh.painuly@derbyshcft.nhs.uk)

First received 5 Jul 2011, final revision 5 Jan 2013, accepted 17 Jan 2013

\begin{abstract}
Aims and method To examine the association between the use of paroxetine during pregnancy and the risk of cardiovascular defects in the newborn. A systematic review of nine electronic databases was carried out and bibliographies were hand-searched for other relevant articles. Inclusion criteria for studies were the use of selective serotonin reuptake inhibitors in the first trimester of pregnancy, with separate data available for paroxetine and cardiovascular defects in newborn babies. A randomeffect model was used to combine the data.
\end{abstract}

Results A total of 11 studies were included in the analysis, concerning 4515 offspring who were exposed to paroxetine in the first trimester and 1469302 controls. In pooled analysis, paroxetine in the first trimester of pregnancy was slightly, but significantly, associated with a risk of cardiovascular malformations in the offspring (relative risk $=1.25,95 \% \mathrm{Cl} 1.01-1.54$ ). Separate analyses of case-control and cohort studies made this difference non-significant.

Clinical implications This meta-analysis supports current guidelines advising not to use paroxetine in early pregnancy.

Declaration of interest P.S. received a research grant as a principal investigator from Eli Lilly for a project that was completed about 6 months prior to his involvement in this study.
Depression during pregnancy is a major public health concern. It is highly prevalent and causes considerable suffering and impairment to the mother and has possible adverse consequences for the newborn. ${ }^{1-4}$ Selective serotonin reuptake inhibitors (SSRIs) are the most commonly prescribed antidepressants during pregnancy ${ }^{4}$ and until recently were considered safe in this period. ${ }^{5}$ However, database and case-control studies have reported an association between SSRIs and anencephaly, craniosynostosis, omphalocele and persistent pulmonary hypertension in newborn children, although these associations have not been replicated in other studies. ${ }^{4,6}$ First-trimester exposure to paroxetine has been associated with cardiovascular malformations in some studies, ${ }^{7,8}$ however, other studies have failed to replicate this finding., 4

We have conducted a meta-analysis with the aim of examining the suggested association between the use of paroxetine during pregnancy and the risk of cardiovascular defects in newborn children.

\section{Method}

We used the search engine Dialog ${ }^{\mathrm{TM}}$ (formerly, DataStar ${ }^{\circledR}$ ) provided by the National Library of Health that includes the following databases: PubMed, Embase, PsycINFO, Social
Sciences Citation Index (SSCI), King's Fund, DH-Data, CINAHL, Allied and Complementary Medicine Database (AMED) and British Nursing Index (BNI). Combinations of the terms 'SSRI', 'selective serotonin reuptake inhibitor(s)', 'SRI', 'serotonin reuptake inhibitors', 'paroxetine', 'pregnancy', 'congenital malformation(s)', 'congenital defect(s)', 'cardiovascular malformation(s)', 'cardiac $\operatorname{defect}(\mathrm{s})$ ', 'cardiovascular defect(s)', 'fetal malformation(s)' and 'fetal anomalies' were used for the search. The search was restricted to articles published in English but there was no exclusion on the basis of country, ethical approval, etc. No grey literature was searched for this review. Each abstract/title and article was scrutinised by two of the authors (N.P. and R.P.) and the differences between them were resolved by consensus. Relevant articles were hand-searched for cross-references. The GlaxoSmithKline website was searched for recent data on paroxetine. To exclude repetitive data-sets, only the study with the most updated data was taken up for analysis. A repeat data search was done in August 2012, after the first review of this article, and results were updated.

\section{Inclusion and exclusion criteria}

We included studies that met the following criteria:

1 use of SSRIs in the first trimester of pregnancy, with separate data available for paroxetine 
2 control group of unexposed women available for comparison

3 as an outcome, separate data available for congenital cardiovascular defects in newborns, for instance conotruncal heart defects, septal heart defects, ventricular outflow tract obstruction.

Exclusion criteria were:

1 papers published on repeat data

2 studies with no control group for comparison

3 no cardiovascular defect in both study and control group.

Excluded studies are presented in online Table DSl.

The modified QUOROM Flow Chart ${ }^{10}$ (Fig. 1) was used to show the study search process.

\section{Outcome measure}

The outcome measure for this review was cardiovascular malformation in the newborn.

\section{Data collection and analysis}

We collected data from the studies that met the selection criteria. The quality of studies was assessed by criteria adapted from Centre for Reviews and Dissemination guidelines. ${ }^{\text {Il }}$ Descriptive data were mainly expressed in actual numbers of exposed mothers and controls. Where exact numbers were not available, frequencies were changed into actual numbers (described odds ratios (ORs) were used to resolve doubts). Results were presented in terms of risk ratio (RR) with $95 \%$ confidence intervals. A funnel plot was used to assess publication bias and heterogeneity among studies was analysed by the $\chi^{2}$-test. A random-effect model was applied to combine the data. Subgroup analysis was carried out for cohort and case-control studies separately. Sensitivity analysis was carried out by the sequential removal of studies with maximum weight. Data analysis was performed with Review Manager (RevMan 5.0) for Windows. A checklist recommended by the Meta-analysis of Observational Studies in Epidemiology (MOOSE) group ${ }^{12}$ was used.

\section{Results}

The systematic search identified 29 relevant studies. Only 11 studies ${ }^{6,8,9,13-19,21}$ could be included in the analysis, 7 cohort $^{6,14-17,19,21}$ and 4 case-control studies ${ }^{8,9,13,18}$ (Table 1). The total number of individuals included in the metaanalysis was 4514 in the paroxetine group and 1469302 in the control group.

\section{Quality analysis}

As shown in Table 1, the studies that met the selection criteria were from all grades except grade B and the lowest grade $\mathrm{E}$ on the Centre for Reviews and Dissemination hierarchy of observational studies. ${ }^{11}$

\section{Publication bias}

The funnel plot (Fig. 2) shows the relative absence of smallsample sized studies which showed teratogenic effect of paroxetine. In trim-and-fill analysis, three studies on the left side of the plot were trimmed, but the adjusted risk ratio for the main analysis remained significant $(\mathrm{RR}=1.23$, 95\% CI 1.05-1.42).

\section{Test of heterogeneity}

Examination of the $\chi^{2}$ distribution showed that there was significant heterogeneity between the studies included in the main analysis $(\mathrm{Q}=14.34$, d.f. $=10, P=0.1)$. In the subgroup analysis, there was no significant heterogeneity within case-control $(\mathrm{Q}=0.4$, d.f. $=3, P=0.9)$ and cohort $(\mathrm{Q}=8.22$, d.f. $=6, P=0.2)$ studies.

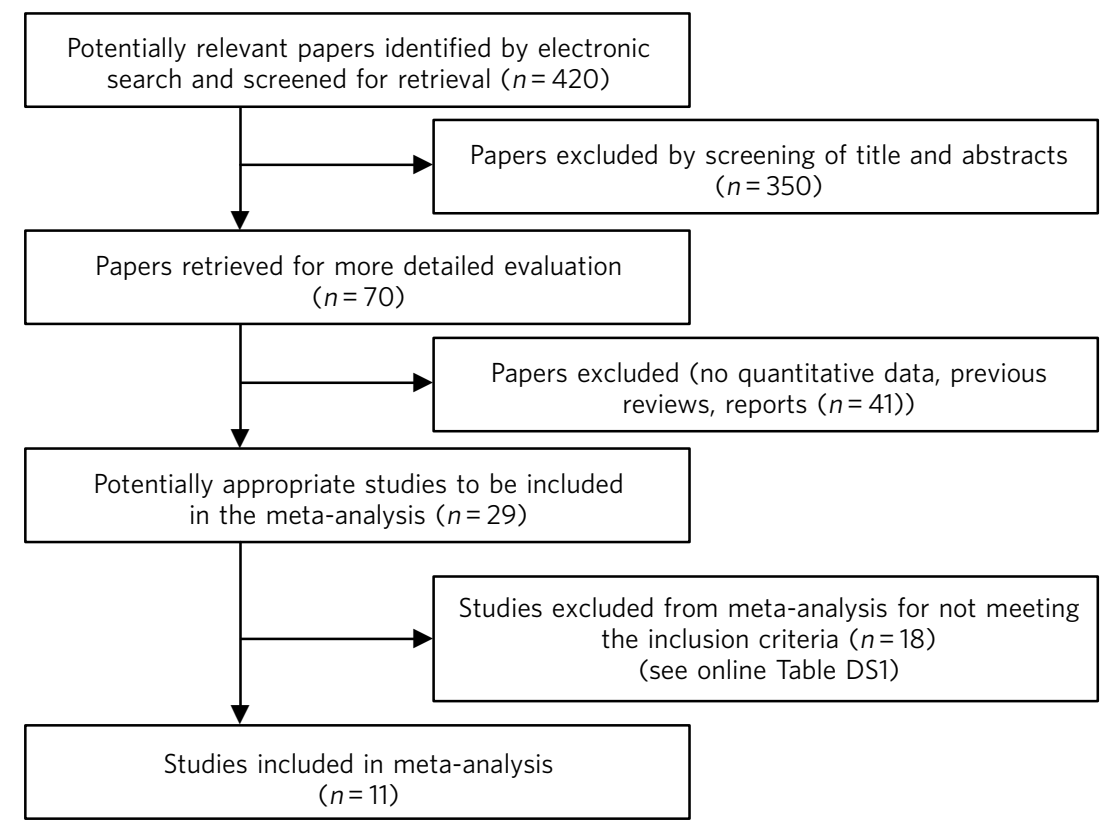

Fig 1 Modified QUORON flow chart $^{10}$ describing the search process. 


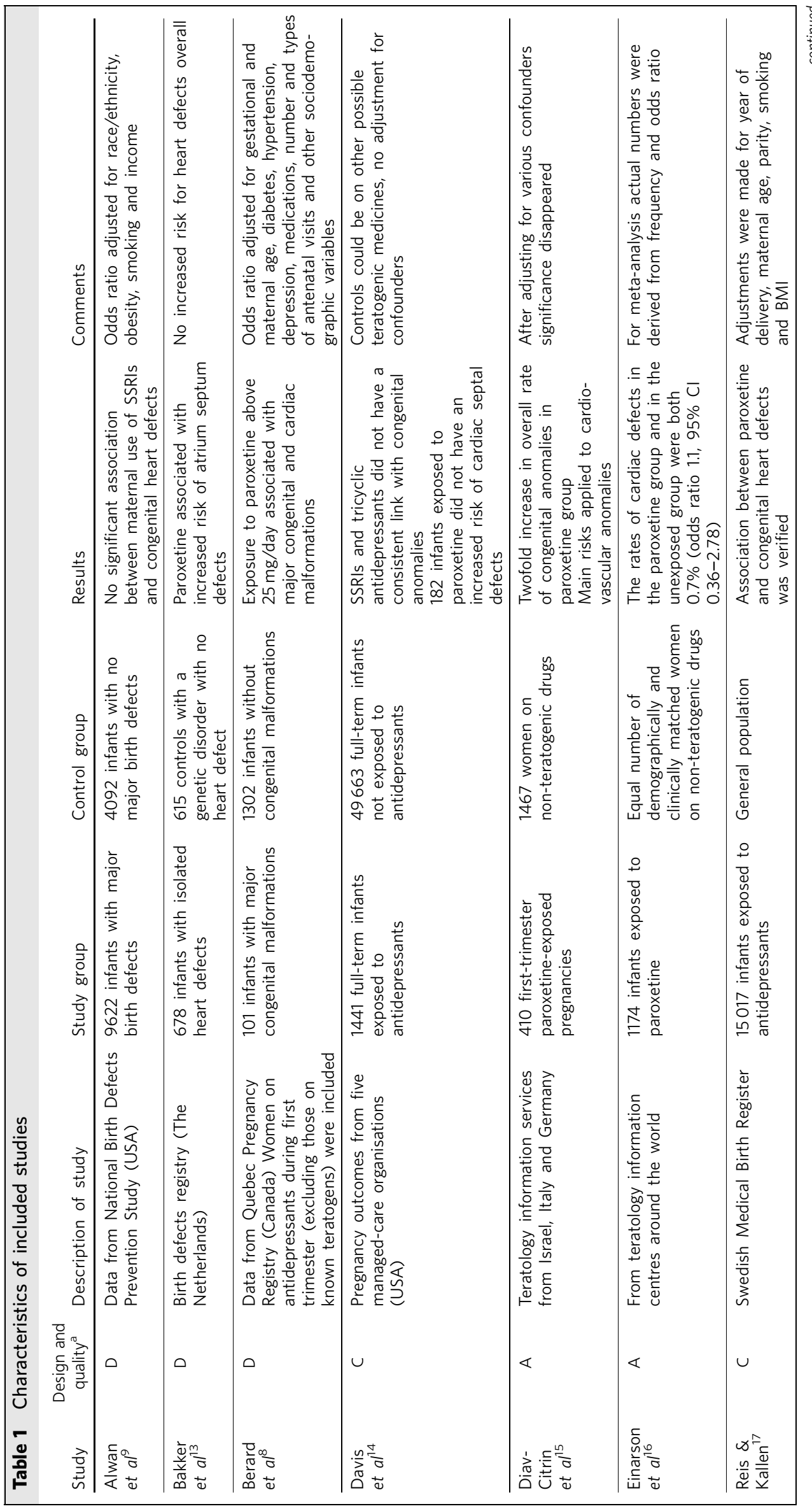




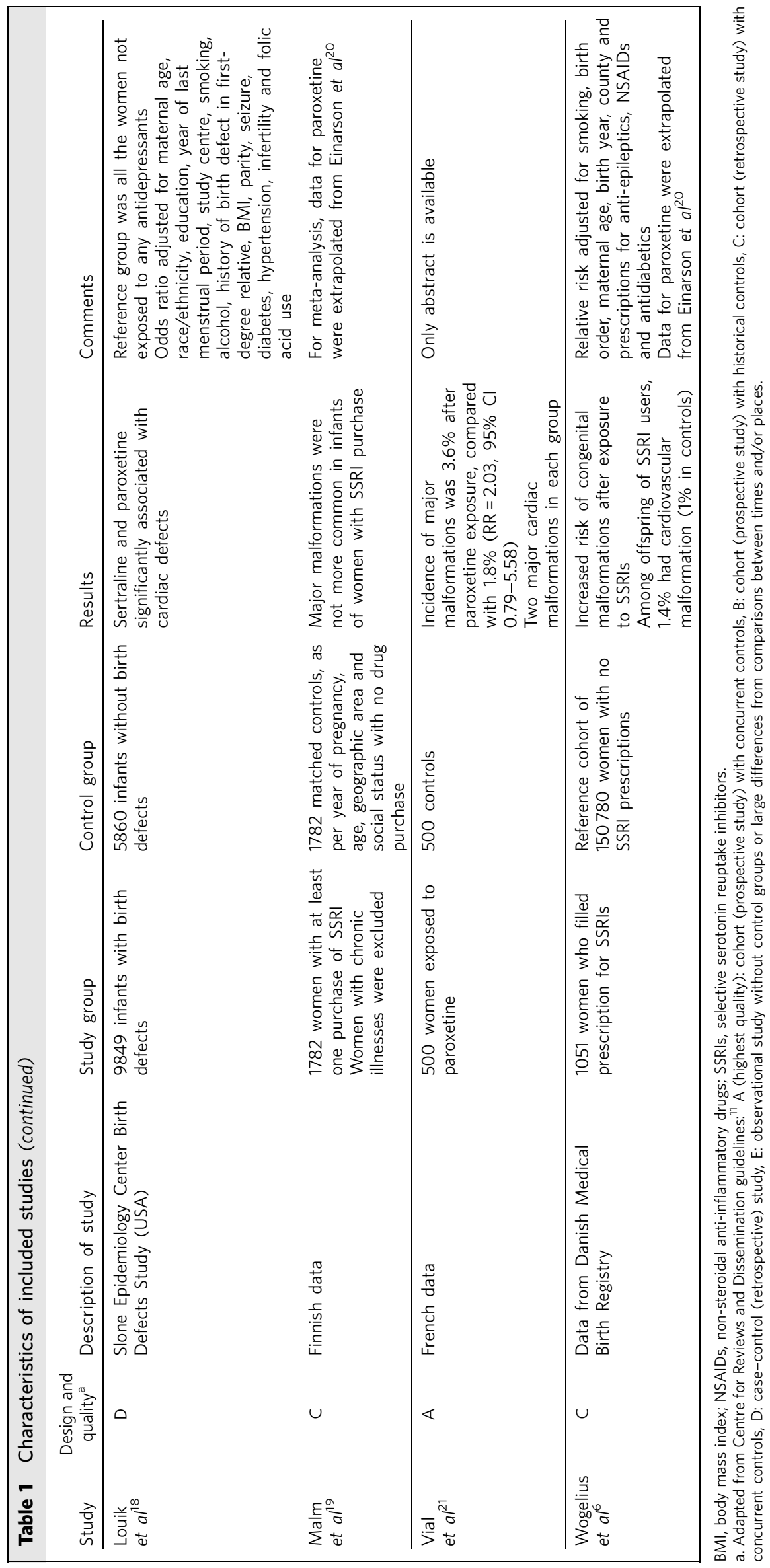




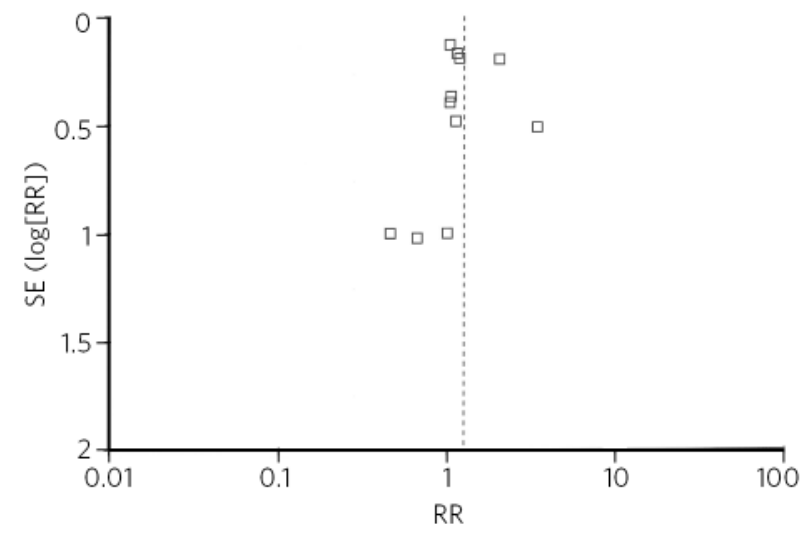

Fig 2 Funnel plot of studies included in the meta-analysis. RR, risk ratio; SE, standard error.

\section{Pooled results}

Paroxetine use in the first trimester of pregnancy was found to be significantly associated with cardiovascular malformations, compared with unexposed controls $(\mathrm{RR}=1.25,95 \% \mathrm{CI}$ 1.01-1.54) (Fig. 3).

\section{Subgroup analysis}

Risk of cardiovascular malformation with paroxetine group became non-significant when data were pooled separately for case-control (RR=1.09, 95\% CI 0.91-1.30) and cohort $(\mathrm{RR}=1.52,95 \%$ CI $0.98-2.34)$ studies.

\section{Sensitivity analysis}

In sequential removal of studies with maximum effect sizes, the difference between paroxetine and the unexposed control remained significant after excluding the studies by Alwan et $a l^{9}$ and Louik et $a l^{18}(\mathrm{RR}=1.38,95 \%$ CI 1.02-1.86). Individually, exclusion of studies by Bakker et $a l^{13}(\mathrm{RR}=1.27$, 95\% CI 0.98-1.64), Louik et $a l^{18}(\mathrm{RR}=1.28,95 \%$ CI 0.98-1.66) or Reis \& Kallen $^{17}(\mathrm{RR}=1.11$, CI $0.94-1.31)$ made the pooled result non-significant.

\section{Discussion}

The validity of meta-analysis of observational studies has always been debated, as observational studies are more prone to biases when compared with the gold-standard randomised controlled trials. ${ }^{22}$ However, a meta-analysis of observational studies seems justified for assessing the teratogenic effect of medications used during pregnancy because experimental studies cannot be conducted and large samples are required to observe rare events such as specific congenital malformations. In recognition of the limitations of meta-analysis of observational studies, we applied a random-effect model (rather than a fixed-effect model) to combine the results, as it can be applied irrespective of the level of heterogeneity of studies. Combining case-control and cohort studies is a wellrecognised practice in meta-analysis of epidemiological studies, ${ }^{12,23}$ although we also carried out a subgroup analysis for case-control and cohort studies separately. Further, we performed a sensitivity analysis to assess the robustness of results. For quality analysis of the studies, the key components of design were considered, as this method has been found to be more appropriate for meta-analysis of observational studies. ${ }^{12}$ In general, the study met the requirements of the MOOSE guidelines. ${ }^{12}$

Although more than half of the identified studies were excluded from the analysis, most of them presented repeat data; thus, the combined results can be taken as a fair representation of the identified studies. There may be some doubts as to the reliability of actual numbers, as in some studies numbers were extrapolated from the frequencies and odds ratios; however, this should not affect the results considerably bearing in mind the large size of the collective sample. The apparent discrepancy between sample size and weight for each study (Fig. 1) corroborates the fact that in meta-analysis, weight given to a particular study depends not only on the sample size, but also on the variance of the data.

Underrepresentation of positive studies with small sample size in publication bias analysis could be a reflection of Type II error, a likely outcome in view of the rarity of the

\begin{tabular}{|c|c|c|c|c|c|c|c|c|c|}
\hline \multirow[b]{2}{*}{ Study or subgroup } & \multicolumn{2}{|c|}{ Paroxetine } & \multicolumn{2}{|c|}{ Unexposed controls } & \multirow[b]{2}{*}{ Weight, \% } & \multirow[t]{2}{*}{ Risk ratio } & \multirow{2}{*}{\multicolumn{2}{|c|}{$\begin{array}{c}\text { Risk ratio } \\
\mathrm{M}-\mathrm{H} \text {, random, } 95 \% \mathrm{Cl}\end{array}$}} & \\
\hline & Events & Total & Events & Total & & & & & \\
\hline Alwan et $a l^{9}$ & 32 & 70 & 4268 & 9622 & 23.7 & $1.03(0.80,1.33)$ & & & \\
\hline Bakker et al ${ }^{13}$ & 10 & 16 & 678 & 1277 & 16.6 & $1.18(0.80,1.73)$ & & & \\
\hline Berard et $a l^{8}$ & 10 & 552 & 24 & 1403 & 6.9 & $1.06(0.51,2.20)$ & & & \\
\hline Davis et $a l^{14}$ & 6 & 182 & 1594 & 49654 & 6.1 & $1.03(0.47,2.26)$ & & & \\
\hline Diav-Citrin et $a l^{15}$ & 7 & 348 & 8 & 1359 & 4.0 & $3.42(1.25,9.36)$ & & & \\
\hline Einarson et $\mathrm{al}^{16}$ & 9 & 1174 & 8 & 1174 & 4.4 & $1.13(0.44,2.91)$ & & & \\
\hline Louik et $a l^{18}$ & 25 & 96 & 3601 & 15709 & 18.9 & $1.14(0.81,1.59)$ & & & \\
\hline Malm et al ${ }^{19}$ & 1 & 149 & 18 & 1771 & 1.1 & $0.66(0.09,4.91)$ & & & \\
\hline Reis \& Kallen ${ }^{17}$ & 24 & 1208 & 11910 & 1236053 & 16.0 & $2.06(1.39,3.07)$ & & - & \\
\hline Vial et $a l^{21}$ & 2 & 500 & 2 & 500 & 1.2 & $1.00(0.14,7.07)$ & & & \\
\hline Wogelius et $a l^{6}$ & 1 & 219 & 1508 & 150780 & 1.2 & $0.46(0.06,3.23)$ & & & \\
\hline Total $(95 \% \mathrm{Cl})$ & & 4514 & & 1469302 & 100.0 & $1.25(1.01,1.54)$ & & & \\
\hline Total events & 127 & & 23619 & & & & & & \\
\hline \multicolumn{9}{|c|}{ Heterogeneity: $\tau=0.03 ; \chi^{2}=14.34$, d.f. $=10(P=0.16) ; I^{2}=30 \%$} & -1 \\
\hline \multicolumn{6}{|c|}{ Test for overall eect: $Z=2.03(P=0.04)$} & 0.01 & 0.1 & 10 & 100 \\
\hline
\end{tabular}

Fig 3 Risk of cardiovascular malformations with first-trimester use of paroxetine in comparison with unexposed controls (forest plot). M- $\mathrm{H}$, Mantel-Haenszel method. 
occurrence of cardiovascular defects. The trim-and-fill analysis only confirmed the limitation of this method, as it does not take into account the reasons for funnel plot asymmetry other than publication bias.

Our meta-analysis, based on largest collective data sample so far, suggests that offspring of women who are exposed to paroxetine in the first trimester of pregnancy are at a small but significant increased risk of cardiovascular malformations. However, subgroup analysis and sensitivity analysis shows the fragility of this association. It is also possible that the borderline significant results of our meta-analysis could disappear, if the crude numbers used for the combined analysis were adjusted for various confounders such as maternal age, race, smoking, medical comorbidities, concomitant use of possible teratogens, etc.

Results of our meta-analysis fall in line with two other meta-analyses. ${ }^{24,25}$ O'Brien et $\mathrm{al}^{24}$ separately analysed three case-control $(n=30247)$ and six cohort $(n=66409)$ studies and they did not find any significant association of cardiac malformation with paroxetine exposure. On the other hand, meta-analysis by Wurst et $a l^{25}$ combined ten cohort and four case-control studies $(n=109958)$ and found an increased prevalence of cardiac defects with first-trimester paroxetine use $(\mathrm{OR}=1.46,95 \% \mathrm{CI} 1.17-1.82)$. Whether it is the large sample size which overcomes Type II error and exposes the teratogenic potential of paroxetine or too much heterogeneity (for the sake of large sample size) that brings spurious association remains debatable. In future, an analysis with large but more homogeneous data might provide the answer. In the meantime, our meta-analysis suggests that there is a possibility that exposure to paroxetine could be significantly associated with cardiovascular malformations and in that sense it supports the existing guidelines, ${ }^{4,26}$ which advise avoiding paroxetine use in early pregnancy.

\section{About the authors}

Nitesh Painuly is consultant psychiatrist, Derbyshire Healthcare NHS Foundation Trust, Derby, UK; Ritu Painuly is specialty registrar (obstetrics and gynaecology), Royal Derby Hospital, Derby, UK; Reinhard Heun is consultant psychiatrist, Derbyshire Healthcare NHS Foundation Trust, Derby, UK; Pratap Sharan is professor of psychiatry, Department of Psychiatry, All India Institute of Medical Sciences, New Delhi, India.

\section{References}

1 Zuckerman B, Amaro H, Bauchner H, Cabral H. Depressive symptoms during pregnancy: relationship to poor health behaviours. Am J Obstet Gynecol 1989; 160: 1107-11.

2 Bennett HA, Einarson A, Taddio A, Koren G, Einarson TR. Prevalence of depression during pregnancy: systematic review. Obstet Gynecol 2004; 103: $698-709$.

3 Stewart RC. Maternal depression and infant growth: a review of recent evidence. Matern Child Nutr 2007; 3: 94-107.

4 Taylor D, Paton N. Kapur S. The Maudsley Prescribing Guidelines in Psychiatry. Wiley-Blackwell, 2012.

5 Wen SW, Yand Q, Garner P, Fraser W, Olatunbosun O, Nimrod C, et al. Selective serotonin reuptake inhibitors and adverse pregnancy outcomes. Am J Obstet Gynecol 2006; 194: 961-6.

6 Wogelius P, Norgaad M, Gislum M, Pedersen L, Munk E, Mortensen PB, et al. Maternal use of selective serotonin reuptake inhibitors and risk of cardiovascular malformations. Epidemiology 2006; 17: 701-4.
7 Kallen BJ, Olausson PO. Maternal use of selective serotonin re-uptake inhibitors in early pregnancy and infant congenital malformations. Birth Defects Res (Part A) 2007; 79: 301-8.

8 Berard A, Ramos E, Rey E, Blais L, St-Andre M, Oraichi D. first trimester exposure to paroxetine and risk of cardiac malformations in infants: the importance of dosage. Birth Defect Res (Part B) 2007; 80: 18-27.

9 Alwan S, Reefhuis J, Rasmussen SA, Olney RS, Friedman JM. Use of selective serotonin-reuptake inhibitors and the risk of birth defects. N Engl J Med 2007; 356: 2684-92.

10 Mohler D, Cook D, Eastwood S, Olkin I, Rennie D, Stroup D, et al. Improving quality of reports of meta-analyses of randomised controlled trials: the QUOROM statement. Lancet 1999; 354: 1896-900.

11 Centre for Reviews and Dissemination. CRD's Guidance for Undertaking Reviews in Health Care. CRD, 2008 (http://www.york.ac.uk/inst/crd/ SysRev/!SSL!/WebHelp/SysRev3.htm).

12 Stroup DF, Berlin JA, Morton SC, Olkin I, Williamson GD, Rennie D. Meta-analysis of observational studies in epidemiology: a proposal for reporting. JAMA 2000; 283: 2008-12.

13 Bakker MK, Kerstjens-Frederikse WS, Buys $\mathrm{CH}$, de Walle $\mathrm{HE}$, de Jongvan den Berg LT. First-trimester use of paroxetine and congenital heart defects: a population-based case-control study. Birth Defects Res A Clin Mol Teratol 2010; 88: 94-100.

14 Davis RL, Rubanowice D, McPhillips H, Raebal MA, Andrade SE, Smith D, et al. Risks of congenital malformations and perinatal events among infants exposed to antidepressant medications during pregnancy. Pharmacoepidemiol Drug Saf 2007; 16: 1086-94.

15 Diav-Citrin O, Shechtman S, Weinbaum D, Wajnberg R, Avgil M, Di Gianantonio $E$, et al. Paroxetine and fluoxetine in pregnancy: a prospective, multicentre, controlled, observational study. $\mathrm{Br}$ Pharmacol 2008; 66: 695-705.

16 Einarson A, Pistelli A, DeSantis M, Malm H, Paulus WD, Panchaud A, et al. Evaluation of the risk of congenital cardiovascular defects associated with use of paroxetine during pregnancy. Am J Psychiatry 2008; 165 749-52.

17 Reis M, Kallen B. Delivery outcome after maternal use of antidepressant drugs in pregnancy: an update using Swedish data. Psychol Med 2010; 40: $1723-33$.

18 Louik C, Angela EL, Werler MM, Hernandez-Diaz S, Mitchell AA. First trimester use of selective serotonin reuptake inhibitors and the risk of birth defects. N Engl J Med 2007; 356: 2675-83.

19 Malm H, Klaukka T, Newvonen PJ. Risks associated with selective serotonin reuptake inhibitors in pregnancy. Obstet Gynecol 2005; 106 1289-96.

20 Einarson A, Pistelli A, DeSantis $M$, Malm H, Paulus WD, Panchaud A et al. Evaluation of the risk of congenital cardiovascular defects associated with use of paroxetine during pregnancy. Am J Psychiatry 2008; 165: 749-52.

21 Vial T, Bernard N, Carlier P, Jonville-Bera AP, Jean-Pastor MJ, Barjhoux $C$, et al. Paroxetine and congenital malformations: a prospective comparative study. Fundamental Clin Pharmacol 2006; 20: 223 (abstract no 228)

22 Spitzer WO. Meta-meta-analysis: unanswered questions about aggregating data. J Clin Epidemiol 1991; 44: 103-7.

23 Schlesselman JJ. Risk of endometrial cancer in relation to use of combined oral contraceptives: a practitioner's guide to meta-analysis. Hum Reprod 1997; 12: 1851-63.

24 O'Brien L, Einarson TR, Sarkar M, Einarson A, Koren G. Does paroxetine cause cardiac malformations? J Obstet Gynaecol Can 2008; 30: 696701.

25 Wurst KE, Poole C, Ephross SA, Olshan AF. First trimester paroxetine use and the prevalence of congenital, specifically cardiac, defects: a meta-analysis of epidemiological studies. Birth Defects Res A Clin Mol Teratol 2010; 88: 159-70.

26 National Institute for Health and Clinical Excellence. Understanding NICE Guidance - Information for People who Use NHS Services: Mental Health Problems During Pregnancy and After Giving Birth. NICE, 2007 (http:// www.nice.org.uk/nicemedia/pdf/CG045Publiclnfo.pdf). 